\title{
Effect of Carrying a Rifle on Physiology and Biomechanical Responses in Biathletes
}

\author{
THOMAS STÖGGL ${ }^{1,2}$, PHIL BISHOP ${ }^{2,3}$, MARTINA HÖÖK ${ }^{2}$, SARAH WILLIS ${ }^{2}$, and HANS-CHRISTER HOLMBERG ${ }^{2,4}$ \\ ${ }^{1}$ Department of Sport Science and Kinesiology, University of Salzburg, Salzburg, AUSTRIA; ${ }^{2}$ Department of Health Sciences, \\ Swedish Winter Sports Research Centre, Mid-Sweden University, Östersund, SWEDEN; ${ }^{3}$ Department of Exercise Science and \\ Kinesiology, University of Alabama, Tuscaloosa, AL; and ${ }^{4}$ Swedish Olympic Committee, Stockholm, SWEDEN
}

\begin{abstract}
STÖGGL, T., P. BISHOP, M. HÖÖK, S. WILLIS, and H. HOLMBERG. Effect of Carrying a Rifle on Physiology and Biomechanical Responses in Biathletes. Med. Sci. Sports Exerc., Vol. 47, No. 3, pp. 617-624, 2015. Purpose: This study aimed to assess the effect of carrying a rifle on the physiological and biomechanical responses of well-trained biathletes. Methods: Ten elite biathletes (five men and five women) performed ski skating with (R) or without a rifle (NR) on a treadmill using the V2 ( $5^{\circ}$ incline) and V1 techniques $\left(8^{\circ}\right)$ at 8 and $6 \mathrm{~km} \cdot \mathrm{h}^{-1}$, respectively, as well as at racing intensity (approximately $95 \%$ of peak oxygen uptake $\left(\mathrm{V}_{2}\right.$ peak $), 10.7 \pm 0.8$ and $7.7 \pm 0.9 \mathrm{~km} \cdot \mathrm{h}^{-1}$, respectively). $\dot{\mathrm{VO}}_{2}$, ventilation $\left(\dot{\mathrm{V}}_{\mathrm{E}}\right)$, HR, blood lactate concentration (BLa), and cycle characteristics as well as pole and leg kinetics were evaluated during these trials. Results: Metabolic data were all higher for R than for NR, as follows: $\dot{\mathrm{VO}}_{2},+2.5 \%$; $\dot{\mathrm{V}}_{\mathrm{E}},+8.1 \%$; RER, $+4.2 \%$; all $P<0.001 ; \mathrm{HR},+1.7 \%$; and BLa, $+15.1 \%$; both $P<0.05$. Biomechanically, carrying a rifle reduced cycle time and length, poling and arm swing times, and leg ground contact time and increased cycle rate, the peak and impulse of leg force, average cycle force, and impulse of forefoot force (all $P<0.05$ ). With the exception of elevated pole forces when V2 skating at racing velocity, there were no differences between the peak and impulse of pole force. The difference in $\dot{\mathrm{V}}_{\mathrm{E}}$ between $\mathrm{R}$ and $\mathrm{NR}$ was greater for the women than that for men $(P<0.05)$, and the difference in BLa also tended to be larger for the women $(P<0.1)$. Conclusions: Carrying a rifle elevated physiological responses, accelerated cycle rate, and involved greater leg work, with no differences between the V1 and V2 techniques. Key Words: CROSSCOUNTRY SKIING, SKATING, ECONOMY, ENERGY COST, RIFLE CARRIAGE
\end{abstract}

$\mathrm{T}$ he biathlon is an Olympic winter sport involving high-intensity cross-country skiing using the skating technique interspersed with 2-4 sessions of rapid and accurate shooting $(4,13)$. On the basis of shooting performance, extra distance or time is added and the biathlete who finishes in the shortest total time wins. Thus, a successful biathlete is a good marksman and an endurance athlete who can ski rapidly using different skating techniques with a rifle on his/her back.

In contrast to the large number of investigations on crosscountry skiing, research concerning the biathlon is scarce. The majority of such studies have focused on shooting performance $(2,8-11,16,17,30)$, and there has been minimal examination of the physiological and biomechanical aspects of skiing.

Address for correspondence: Thomas Stöggl, Associate Professor Mag. Dr., Department of Sport Science and Kinesiology, Schlossallee 49, 5400 Hallein/ Rif, Austria; E-mail: thomas.stoeggl@sbg.ac.at.

Submitted for publication March 2014.

Accepted for publication June 2014.

0195-9131/15/4703-0617/0

MEDICINE \& SCIENCE IN SPORTS \& EXERCISE $_{\circledast}$ Copyright $(C) 2014$ by the American College of Sports Medicine

DOI: 10.1249/MSS.0000000000000438
When using the skating technique, competitive skiers use four main subtechniques, as follows: V1 involves asymmetrical poling on every second leg stroke; V2 is performed on level terrain and moderate uphill inclines and is characterized by single poling on every leg stroke; V2 alternate for use on level terrain, involves symmetrical poling on every second leg stroke; and leg skating, adopted mainly on downhill slopes, involves skating without poling (1).

One fundamental difference between biathlon and crosscountry skiing is the extra load of the rifle that must be carried in the biathlon. Fredrick (6) modeled the additional cost of a 4 - to $5-\mathrm{kg}$ rifle as approximately $7 \%$. Later, Rundell and Szmedra (20) reported a $4 \%-8 \%$ higher oxygen cost, $6 \%-11 \%$ greater ventilation $\left(\dot{\mathrm{V}}_{\mathrm{E}}\right)$, and more pronounced lactate response while carrying a rifle weighing $3.5 \mathrm{~kg}$ during treadmill roller skiing (V2 alternate) on a moderate incline $\left(4.6^{\circ}\right)$ at submaximal velocities $\left(8.9-10.5 \mathrm{~km} \cdot \mathrm{h}^{-1}\right)$. Moreover, the difference in oxygen cost was greater for women, which was proposed by investigators to be due to the higher proportional weight of the rifle.

From a more general perspective, early work on the energy costs of load carriage by Taylor et al. (29) found that the energy costs of load carriage were related directly to the mass of the supported load. In contrast, Heglund et al. (12) found that experienced East African load carriers actually reduced the load-specific mechanical work of load carriage and the reduction increased with an increase in load. More 
specifically, the increase in mechanical work when carrying a load was found to be related to the "experience" of the carrier; for inexperienced load carriers, the load-specific mechanical work increased with the mass of the load whereas the experienced load carriers used a "... pendulumlike transfer of energy during each step ..." to achieve the increase in efficiency. In biathletes, the load is quite small (approximately $4 \mathrm{~kg}$ ) in relation to body weight, suggesting minimal increase in energy costs. Furthermore, a small increase in energy cost when carrying a rifle could also be expected in elite biathletes because they are "quite experienced" in this specific motor task.

The only available report on biomechanical parameters during the biathlon documented reduction in cycle length and increased cycle rate when skiing with a rifle (20). Moreover, this increase in cycle length was associated with greater rise in the blood concentration of lactate and higher oxygen cost for women. To date, the only skating technique investigated in connection with the biathlon has been the V2 alternate, performed at an incline of $4.6^{\circ}$, even though the most common techniques in this event are V1 and V2 and these are performed at various inclines (25). Furthermore, the combined physiological and biomechanical responses (including both kinetics and kinematics) during a biathlon have not yet been examined.

Therefore, the present investigation was designed to characterize physiological and biomechanical parameters and the effect of carrying a rifle on these responses in well-trained biathletes skiing at different intensities with the V1 and V2 skating techniques. Our hypothesis was that carrying a rifle has a greater effect on physiological and biomechanical responses when using the V1 than the V2 technique because the gravitational component acting against the direction of skiing is higher in the former case.

\section{METHODS}

Subjects. Well-trained Swedish biathletes (five men and five women), including members of the Swedish National Team, volunteered to participate (Table 1) and were all fully informed of the nature of this investigation before providing their written consent to participate. This study was preapproved by the regional ethical review board of Umeå University, Umeå, Sweden (\#2012-171-31 M).
Design. On the first day, $\mathrm{V}_{2 \text { peak }}$ using the V2 and V1 skating techniques (in that order) was determined. On the second day, at least $48 \mathrm{~h}$ after the first testing session, the participants performed counterbalanced repeated-measures trials using these two different techniques (in the same order) with (R) or without (NR) a rifle (in a randomized counterbalanced order) at submaximal $\left(80 \% \pm 6.4 \% \dot{\mathrm{VO}}_{2 \text { peak }}\right)$ and racing (approximately $95 \% \pm 1.2 \% \mathrm{VO}_{2 \text { peak }}$ ) intensities (the independent variables), during which physiological and biomechanical parameters (the dependent variables) were monitored. These speeds and inclines were chosen to represent typical competitive conditions.

Roller skis, treadmill, and rifle. For all testing, the same pair of roller skis (Pro-Ski S2; Sterners, Nyhammar, Sweden) with a rolling resistance friction coefficient of $\mu_{R}=$ 0.013 (measured on the treadmill surface in a similar setup by Stöggl et al. (28)) was used. All tests were performed on a ski treadmill (Rodby, Sodertalje, Sweden) large enough (belt dimension, $3.3 \times 2.5 \mathrm{~m}$ ), so that the roller skis could be maneuvered easily and with and without his/her own rifle $(4.0 \pm 0.2 \mathrm{~kg})$ on the back. Each subject was accustomed to roller skiing on the treadmill at high speeds as part of both his/her training and testing. Throughout the entire testing session, the athletes were secured with a safety harness, which was connected to an emergency brake suspended from a metal bracket above the treadmill.

$\dot{\mathrm{V}} \mathrm{O}_{2 \text { peak }}$ measurements. For the $\dot{\mathrm{V}}_{2 \text { peak }}$ measurements, the biathletes first warmed up for $10 \mathrm{~min}$ with V2 skiing on a $5^{\circ}$ incline and at an intensity of $70 \%$ of $\mathrm{HR}_{\max }$. Then, after being fitted with a mouthpiece and noseclip, each roller-skied at this same incline, initially at $9 \mathrm{~km} \cdot \mathrm{h}^{-1}$ for $1 \mathrm{~min}$, after which the speed was increased by $1 \mathrm{~km} \cdot \mathrm{h}^{-1}$ each $60 \mathrm{~s}$ until volitional exhaustion.

For determination of blood lactate (BLa), a blood sample was taken from the fingertip and analyzed in an automated system (Biosen 5140; EKF Diagnostic GmbH, Magdeburg, Germany). The maximal level of effort was considered to have been attained when $\dot{\mathrm{VO}}_{2}$ reached a constant level, even with increasing intensity of exercise, and the maximal posttest BLa value was $>8 \mathrm{mM}$ (3). The same process was repeated 60 min later using the V1 technique on an incline of $8^{\circ}$ and an initial speed of $6 \mathrm{~km} \cdot \mathrm{h}^{-1}$.

On the basis of these measurements, test speeds for determination of approximately $95 \%$ of $\dot{\mathrm{V}}_{2 \text { peak }}$ (racing speed) with each technique were established. The open-circuit

TABLE 1. Descriptive characteristics (means \pm SD) of the 10 (five men and five women) biathlon athletes who participated.

\begin{tabular}{|c|c|c|c|c|c|c|c|c|c|c|c|c|c|}
\hline & \multirow[b]{2}{*}{ Age (yr) } & \multirow[b]{2}{*}{$\begin{array}{c}\text { Body } \\
\text { Height (m) }\end{array}$} & \multirow[b]{2}{*}{$\begin{array}{c}\text { Body } \\
\text { Mass (kg) }\end{array}$} & \multicolumn{5}{|c|}{ V2 Skating } & \multicolumn{5}{|c|}{ V1 Skating } \\
\hline & & & & $\begin{array}{l}\dot{\mathrm{V}} \mathrm{O}_{2 \text { peak }} \\
\left(\mathrm{L} \cdot \mathrm{min}^{-1}\right)\end{array}$ & $\begin{array}{c}\dot{\mathrm{V}}_{\mathrm{E}} \\
\left(\mathrm{L} \cdot \mathrm{min}^{-1}\right)\end{array}$ & $\begin{array}{c}B_{\mathrm{f}} \\
\left(\mathrm{min}^{-1}\right)\end{array}$ & RER & $\begin{array}{c}V_{\text {race }} \\
\left(\mathrm{km}^{-1} \mathrm{~h}^{-1}\right)\end{array}$ & $\begin{array}{l}\dot{\mathrm{V}} \mathrm{O}_{2 \text { peak }} \\
\left(\mathrm{L} \cdot \mathrm{min}^{-1}\right)\end{array}$ & $\begin{array}{c}\dot{\mathrm{V}}_{\mathrm{E}} \\
\left(\mathrm{L} \cdot \mathrm{min}^{-1}\right)\end{array}$ & $\begin{array}{c}B_{f} \\
\left(\mathrm{~min}^{-1}\right)\end{array}$ & RER & $\begin{array}{c}V_{\text {race }} \\
\left(\mathrm{km}^{-1} \mathrm{~h}^{-1}\right)\end{array}$ \\
\hline Men & $21.6 \pm 2.6$ & $1.74 \pm 0.05$ & $75.3 \pm 6.5$ & $4.6 \pm 0.3$ & $175 \pm 20$ & $69 \pm 3$ & $1.14 \pm 0.05$ & $11.2 \pm 0.8$ & $4.6 \pm 0.4$ & $168 \pm 9$ & $65 \pm 9$ & $1.11 \pm 0.03$ & $8.2 \pm 1.0$ \\
\hline Women & $26.4 \pm 3.6^{\star}$ & $1.70 \pm 0.06$ & $65.0 \pm 3.0^{*}$ & $3.5 \pm 0.4^{\star * *}$ & $136 \pm 14^{* *}$ & $65 \pm 5$ & $1.18 \pm 0.07$ & $10.2 \pm 0.6^{*}$ & $3.5 \pm 0.4^{\star \star \star}$ & $132 \pm 14^{\star \star *}$ & $54 \pm 3^{\star}$ & $1.13 \pm 0.04$ & $7.2 \pm 0.4^{*}$ \\
\hline Combined & $24.0 \pm 3.9$ & $1.72 \pm 0.06$ & $70.2 \pm 7.2$ & $4.1 \pm 0.7$ & $155 \pm 27$ & $67 \pm 4$ & $1.16 \pm 0.05$ & $10.7 \pm 0.8$ & $4.0 \pm 0.7$ & $150 \pm 22$ & $60 \pm 8$ & $1.12 \pm 0.04$ & $7.7 \pm 0.9$ \\
\hline
\end{tabular}

${ }^{\star} P<0.05$, in comparison with the corresponding value for the men.

${ }^{\star \star} P<0.01$, in comparison with the corresponding value for the men.

${ }^{\star * \star} P<0.001$, in comparison with the corresponding value for the men.

$\mathrm{V}_{\text {race, }}$ skiing velocity at $95 \% \dot{\mathrm{V}} \mathrm{O}_{2 \text { peak }}$ of the respective technique. 
metabolic system used (AMIS 2001 model C; Innovision A/S, Odense, Denmark) was calibrated before each test, in accordance with the specifications of the manufacturer, using a 3-L syringe (Hans Rudolph, Kansas City, KS) and a certified mixture of $16 \% \mathrm{O}_{2}$ and $4.5 \% \mathrm{CO}_{2}$. HR was measured using an HR monitor (S610; Polar Electro Oy, Kempele, Finland).

Measurements of physiological and biomechanical variables. After a 10 -min warm-up at $60 \%$ of $\mathrm{HR}_{\max }$, each biathlete performed the test protocol as shown in Figure 1. During the sessions, physiological and biomechanical measurements were made, as will be described later. Before skiing and immediately after completing each test condition, BLa was determined.

Physiological parameters $\left(\dot{\mathrm{VO}}_{2}, \mathrm{HR}, \mathrm{RER}, \dot{\mathrm{V}}_{\mathrm{E}}\right.$, breathing frequency $\left(B_{\mathrm{f}}\right)$, and metabolic rate) were monitored during the final $90 \mathrm{~s}$ of all trials. The metabolic rate (W) was calculated as the sum of the rates of aerobic work (i.e., the product of absolute $\dot{\mathrm{V}}_{2}$ and the energetic equivalent of oxygen, using the associated RER and standard conversion tables (19)) and anaerobic work (calculated from the BLa values after each trial, with 1-mM BLa being equivalent to $3 \mathrm{~mL} \cdot \mathrm{kg}^{-1} \mathrm{O}_{2}$ consumed with an RER of 1.0 (5)). This calculation of metabolic rate was performed according to Sandbakk et al. (24), who studied V2 skating by sprint crosscountry skiers. Furthermore, the proportional increase of the energy cost with respect to the increased system mass by rifle carriage was calculated using the equation of Taylor et al. (29), as follows:

$$
\frac{\mathrm{VO}_{2 \_\mathrm{R}} / \mathrm{VO}_{2 \_\mathrm{NR}}}{\text { system }- \text { mass }_{\mathrm{R}} /{\text { system }- \text { mass }_{\mathrm{NR}}}}
$$

The minimum external work rate was calculated as the sum of the power exerted against gravity (system mass $\times$ sine of the incline $\times$ skiing speed) and against friction (system mass $\times$ cosine of the incline $\times \mu_{R} \times$ skiing speed), where the system mass was equal to the mass of the skier (including equipment) plus the rifle. Gross efficiency was calculated as the ratio between minimum external work and metabolic rate (24). Finally, the metabolic cost of the task was calculated as metabolic power normalized to system mass and skiing speed. This represents the metabolic work required to move $1 \mathrm{~kg}$ of system mass $1 \mathrm{~m}\left(\mathrm{~J} \cdot \mathrm{kg}^{-1} \cdot \mathrm{m}^{-1}\right)$.

Kinematic and kinetic measurements. Cycle characteristics (time, rate, and length) and phases within the poling and leg push-off phases (ground contact times, swing times, etc.) were calculated from the pole and plantar force data. All of the athletes used carbon fiber racing poles adjusted individually to the length normally used and specially constructed for force measurements. The ground reaction force of the pole, directed along the length of the pole, was measured by a strain gauge force transducer mounted directly below the pole grip (Hottinger-Baldwin Messtechnik GmbH, Darmstadt, Germany). This transducer weighed $60 \mathrm{~g}$ and was installed in a lightweight $(75 \mathrm{~g})$ aluminum tube. Plantar ski reaction forces were recorded at $100 \mathrm{~Hz}$ by a mobile system (Pedar; Novel GmbH, Munich, Germany). These systems for measuring pole and plantar forces were validated and calibrated as described elsewhere (14).

Pole forces were recorded by a telemetric system (TeleMyo 2400 T G2; Noraxon, Scottsdale, AZ) and simultaneously at a sampling rate of $1500 \mathrm{~Hz}$ by a computer via an analog-todigital converter card. Synchronization between the pole force and Pedar mobile system was achieved with a signal generated as soon as the system was started. Poling time, arm swing time, leg ground contact time, leg swing time, peak pole and peak leg forces, and impulse of forces for the legs and arms were calculated separately for each side of the body, and the mean of the values for both sides was analyzed.

The entire measuring equipment weighed $1.5 \mathrm{~kg}$ and was installed on a hip belt. For each trial, the mean values of 10 successive cycles during the final $30 \mathrm{~s}$ of each phase were analyzed. All data were processed with the IKE-master software (IKE-Software Solutions, Salzburg, Austria).

Statistical analyses. As a first step, a four-way ANOVA with repeated measures (two speeds, two techniques, R vs NR, gender) was conducted to look for global differences between individual conditions. In a second step, the data for each individual technique were analyzed, applying a two-way repeated-measures ANOVA (two speeds, $\mathrm{R}$ vs NR). When main effects were observed for carrying a rifle and/or speed, paired $t$-tests were performed. In addition, the values obtained were evaluated further by calculating the effect size $\left({ }_{\mathrm{p}} \eta^{2}\right)$. A value of $\alpha<0.05$ was considered statistically significant, and all statistical tests were performed using the Statistical Package for the Social Sciences (version 20.0; SPSS Inc., Chicago, IL).

\section{RESULTS}

For the preliminary testing, $\dot{\mathrm{V}}_{2 \text { peak }}$ and $\dot{\mathrm{V}}_{\mathrm{E}}$ were equal between V2 and V1 skating $(P>0.05)$ whereas RER, $B_{\mathrm{f}}$, and $\mathrm{HR}_{\max }$ were greater during the V2 test (all $P<0.05$ ). Gender comparison revealed greater $\dot{\mathrm{V}}_{2 \text { peak }}(\mathrm{V} 1$ and $\mathrm{V} 2$, $P<0.001), \dot{\mathrm{V}}_{\mathrm{E}}(\mathrm{V} 1, P<0.001 ; \mathrm{V} 2, P<0.01)$, and time to exhaustion (V1 and V2, $P<0.05$ ) for the men compared with those for women (Table 1).

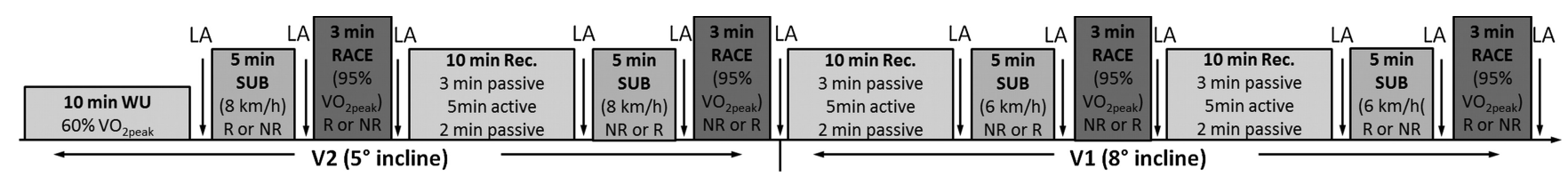

FIGURE 1-Overview of the measurement protocol. WU, warm-up; LA, sampling of BLa; RACE, racing speed at $95 \%$ of the respective $\dot{\mathrm{V}} \mathrm{O}_{2 \text { peak}}$; Rec, recovery; SUB, absolute submaximal speed. 
TABLE 2. Physiological responses and work rates (mean \pm SD) while V2 skating at an absolute submaximal speed $\left(8 \mathrm{~km} \cdot \mathrm{h}^{-1}\right)$ or racing speed $\left(10.7 \mathrm{~km} \cdot \mathrm{h}^{-1}, 95 \% \dot{\mathrm{V}} \mathrm{O}_{2 \text { peak }}\right)$ and an incline of $5^{\circ}$ with or without a rifle $(n=10)$.

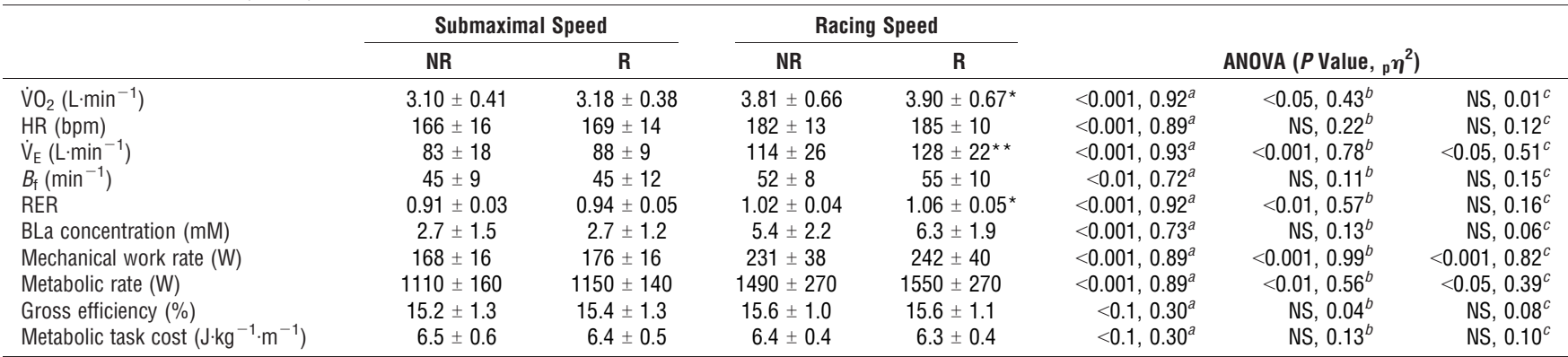

\section{${ }^{a}$ Global effect of speed.}

${ }^{b} \mathrm{Global}$ effect of rifle.

Interaction effect, speed-rifle.

${ }^{\star} P<0.01$, in comparison with the corresponding value without a rifle.

${ }^{\star *} P<0.001$, in comparison with the corresponding value without a rifle.

NS, not statistically significant.

With respect to overall physiological parameters, the main effects (both speeds and pooled R and NR) of carrying a rifle were elevations in $\mathrm{V}_{2}$ (from 3.50 to $3.59 \mathrm{~L} \cdot \mathrm{min}^{-1}$, $+2.5 \%$ ), $\dot{\mathrm{V}}_{\mathrm{E}}$ (from 99 to $107 \mathrm{~L} \cdot \mathrm{min}^{-1},+8.1 \%$ ), RER (from 0.91 to $1.05,+4.2 \%$ ) (all $P<0.001$ ), HR (from 176 to $179 \mathrm{bpm},+1.7 \%$ ), BLa (from 4.3 to $4.9 \mathrm{mM},+15.1 \%$ ) (both $P<0.05$ ), and metabolic work rate (from 1318 to $1374 \mathrm{~W}$, $+4.2 \%, P<0.001$ ) (Tables 2 and 3). The ratio of $\dot{\mathrm{VO}}_{2 \mathrm{R}} /$ $\dot{\mathrm{V}} \mathrm{O}_{2}$ NR to system-mass_R'system-mass_NR ${ }^{-1}$ was 0.97 and equal at all four testing situations (V1 submaximal, V1 race, V2 submaximal, V2 race). Skiing with a rifle also led to an increase in external work rate (from $212 \pm 51$ to $222 \pm 49 \mathrm{~W}$, $P<0.001$ ), with more pronounced increases in the case of V1 than those in V2 $(11.5 \pm 2.0$ vs $10.4 \pm 1.8 \mathrm{~W}, P<0.001)$ and when skiing at racing than at submaximal speed $(9.5 \pm 0.8 \mathrm{vs}$ $12.4 \pm 1.7 \mathrm{~W}, P<0.001)$, demonstrating a lack of any interaction between technique and speed. The gross efficiency and metabolic cost of the task (approximately 16\% and $7.7 \mathrm{~J} \cdot \mathrm{kg}^{-1} \cdot \mathrm{m}^{-1}$, respectively) were not influenced by either carrying a rifle or skiing speed.

From a biomechanical perspective, the main effects of carrying a rifle were reductions in the cycle time and length and duration of pole and leg ground contact and of arm swing (all $P<0.01$ ), along with an accelerated cycle rate $(P<0.001)$. Furthermore, the peak leg force $(P<0.001)$, impulse of leg force $(P<0.05)$, average cycle force $(P<0.01)$, impulse of forefoot force $(P<0.05)$, and mechanical work rate $(P<0.001)$ were all elevated (Tables 4 and 5$)$. With the exception of increased peak pole force with the V2 technique at racing velocity, no differences with respect to the peak and impulse of pole force were observed between R and NR.

The physiological and biomechanical variables examined demonstrated no interaction effects between the technique used and carrying a rifle. The rates of metabolic and mechanical work, gross efficiency, and metabolic cost of the task were greater with the $\mathrm{V} 1\left(8^{\circ}\right)$ than those with the V2 $\left(5^{\circ}\right)$ technique $(1368$ vs $1325 \mathrm{~W}, P<0.01 ; 230$ vs $204 \mathrm{~W}$, $P<0.001 ; 16.9 \%$ vs $15.5 \%, P<0.001$; and 8.9 vs $6.4 \mathrm{~J} \cdot \mathrm{kg}^{-1} \cdot \mathrm{m}^{-1}$, respectively).

Comparison of the male and female athletes revealed main effects for $\mathrm{VO}_{2}$ (men, $29 \%$ higher, 4.0 vs $3.1 \mathrm{~L} \cdot \mathrm{min}^{-1}$, $P<0.001$ ), the rates of metabolic work (men, $29 \%$ greater, 1517 vs $1174 \mathrm{~W}, P<0.01)$ and mechanical work (men, $25 \%$ greater, 241 vs $193 \mathrm{~W}, P<0.01$ ), cycle length (men, $11 \%$

TABLE 3. Physiological responses and work rates (mean \pm SD) while V1 skating at an absolute submaximal speed $\left(6 \mathrm{~km} \cdot \mathrm{h}^{-1}\right)$ or racing speed $\left(7.7 \mathrm{~km} \cdot \mathrm{h}^{-1}, 95 \% \dot{\mathrm{V}} \mathrm{O}_{2 \text { peak }}\right.$ ) and an incline of $8^{\circ}$ with or without a rifle $(n=10)$.

\begin{tabular}{|c|c|c|c|c|c|c|c|}
\hline & \multicolumn{2}{|c|}{ Submaximal Speed } & \multicolumn{2}{|c|}{ Racing Speed } & & & \\
\hline & NR & $\mathbf{R}$ & NR & $\mathbf{R}$ & \multicolumn{3}{|c|}{ ANOVA ( $P$ Value, $\left.p \eta^{2}\right)$} \\
\hline$\dot{\mathrm{V}} \mathrm{O}_{2}\left(\mathrm{~L} \cdot \mathrm{min}^{-1}\right)$ & $3.19 \pm 0.43$ & $3.30 \pm 0.41^{\star \star *}$ & $3.89 \pm 0.78$ & $3.96 \pm 0.78^{*}$ & $<0.001,0.74^{a}$ & $<0.001,0.72^{b}$ & NS, $0.19^{c}$ \\
\hline $\mathrm{HR}$ (bpm) & $171 \pm 14$ & $174 \pm 15^{\star \star \star}$ & $186 \pm 1$ & $187 \pm 10^{*}$ & $<0.001,0.74^{a}$ & $<0.001,0.73^{b}$ & $<0.05,0.41^{c}$ \\
\hline$\dot{\mathrm{V}}_{\mathrm{E}}\left(\mathrm{L} \cdot \mathrm{min}^{-1}\right)$ & $82 \pm 14$ & $88 \pm 13^{\star \star}$ & $117 \pm 28$ & $127 \pm 36^{*}$ & $<0.001,0.76^{a}$ & $<0.01,0.69^{b}$ & NS, $0.04^{c}$ \\
\hline$B_{\mathrm{f}}\left(\mathrm{min}^{-1}\right)$ & $40 \pm 5$ & $42 \pm 5$ & $46 \pm 4$ & $46 \pm 18$ & NS, $0.21^{a}$ & NS, $0.01^{b}$ & NS, $0.01^{c}$ \\
\hline RER & $0.89 \pm 0.05$ & $0.92 \pm 0.06^{\star *}$ & $1.03 \pm 0.05$ & $1.07 \pm 0.06^{*}$ & $<0.001,0.75^{a}$ & $<0.05,0.62^{b}$ & NS, $0.01^{c}$ \\
\hline BLa concentration (mM) & $3.2 \pm 1.7$ & $3.7 \pm 2.1$ & $5.9 \pm 2.2$ & $7.0 \pm 2.4^{\star *}$ & $<0.001,0.83^{a}$ & $<0.05,0.51^{b}$ & NS, $0.23^{c}$ \\
\hline Mechanical work rate (W) & $190 \pm 18$ & $200 \pm 18$ & $258 \pm 52$ & $270 \pm 54$ & $<0.001,0.79^{a}$ & $<0.001,0.98^{b}$ & $<0.001,0.65^{c}$ \\
\hline Metabolic rate (W) & $1140 \pm 160$ & $1200 \pm 150$ & $1530 \pm 330$ & $1600 \pm 330$ & $<0.001,0.79^{a}$ & $<0.001,0.80^{b}$ & $\mathrm{NS}, 0.01^{c}$ \\
\hline Gross efficiency (\%) & $16.8 \pm 1.3$ & $16.7 \pm 1.3$ & $17.0 \pm 1.0$ & $17.0 \pm 1.3$ & NS, $0.25^{a}$ & NS, $0.00^{b}$ & NS, $0.02^{c}$ \\
\hline Metabolic task cost $\left(\mathrm{J} \cdot \mathrm{kg}^{-1} \cdot \mathrm{m}^{-1}\right)$ & $8.9 \pm 0.7$ & $9.0 \pm 0.7$ & $8.9 \pm 0.5$ & $8.8 \pm 0.7$ & $\mathrm{NS}, 0.24^{a}$ & NS, $0.01^{b}$ & NS, $0.04^{c}$ \\
\hline
\end{tabular}

\section{${ }^{a}$ Global effect of speed.}

${ }^{b} \mathrm{Global}$ effect of rifle.

Interaction effect, speed-rifle.

${ }^{\star} P<0.05$, in comparison with the corresponding value without a rifle.

${ }^{* *} P<0.01$, in comparison with the corresponding value without a rifle.

$* * * P<0.001$, in comparison with the corresponding value without a rifle.

NS, not statistically significant. 
TABLE 4. Kinematic and kinetic variables (mean \pm SD) while V2 skating at an absolute submaximal speed $\left(8 \mathrm{~km} \cdot \mathrm{h}^{-1}\right)$ or racing speed $\left(10.7 \mathrm{~km} \cdot \mathrm{h}^{-1}, 95 \% \mathrm{~V}_{2 \text { peak }}\right)$ and an incline of $5^{\circ}$ with or without a rifle $(n=10)$.

\begin{tabular}{|c|c|c|c|c|c|c|c|c|}
\hline \multirow[b]{3}{*}{ Cycle characteristics } & \multirow[b]{3}{*}{ Cycle time (s) } & \multicolumn{2}{|c|}{ Submaximal Speed } & \multicolumn{2}{|c|}{ Racing Speed } & & & \\
\hline & & \multirow{2}{*}{$\begin{array}{c}\text { NR } \\
2.20 \pm 0.16\end{array}$} & \multirow{2}{*}{$\frac{\mathbf{R}}{2.16 \pm 0.13^{\star}}$} & \multirow{2}{*}{$\begin{array}{c}\text { NR } \\
2.04 \pm 0.12\end{array}$} & \multirow{2}{*}{$\frac{\mathbf{R}}{2.00 \pm 0.12^{*}}$} & \multicolumn{3}{|c|}{ ANOVA $\left(P\right.$ Value, $\left.{ }_{p} \eta^{2}\right)$} \\
\hline & & & & & & $<0.001,0.84^{a}$ & $<0.01,0.55^{b}$ & NS, $0.01^{c}$ \\
\hline & Cycle rate (Hz) & $0.46 \pm 0.04$ & $0.47 \pm 0.03^{\star}$ & $0.49 \pm 0.03$ & $0.50 \pm 0.03^{\star}$ & $<0.001,0.84^{a}$ & $<0.01,0.59^{b}$ & NS, $0.00^{c}$ \\
\hline & Cycle length (m) & $4.90 \pm 0.36$ & $4.80 \pm 0.28^{*}$ & $6.14 \pm 0.47$ & $6.03 \pm 0.48^{*}$ & $<0.001,0.92^{a}$ & $<0.01,0.59^{b}$ & $\mathrm{NS}, 0.00^{c}$ \\
\hline & Pole ground contact time (s) & $0.54 \pm 0.05$ & $0.53 \pm 0.04$ & $0.45 \pm 0.04$ & $0.45 \pm 0.05$ & $<0.001,0.92^{a}$ & $\mathrm{NS}, 0.11^{b}$ & NS, $0.01^{c}$ \\
\hline & Arm swing time (s) & $0.56 \pm 0.06$ & $0.55 \pm 0.05$ & $0.57 \pm 0.05$ & $0.55 \pm 0.04^{*}$ & NS, $0.08^{a}$ & $<0.05,0.38^{b}$ & $\mathrm{NS}, 0.01^{c}$ \\
\hline & Leg ground contact time (s) & $1.25 \pm 0.09$ & $1.25 \pm 0.08$ & $1.16 \pm 0.07$ & $1.16 \pm 0.10$ & $<0.001,0.83^{a}$ & $\mathrm{NS}, 0.01^{b}$ & NS, $0.00^{c}$ \\
\hline & Leg swing time (s) & $0.95 \pm 0.09$ & $0.94 \pm 0.13$ & $0.88 \pm 0.07$ & $0.85 \pm 0.05$ & $<0.01,0.62^{a}$ & NS, $0.1^{b}$ & NS, $0.03^{c}$ \\
\hline \multirow[t]{7}{*}{ Leg and arm kinetics } & Peak pole force (N) & $172 \pm 79$ & $178 \pm 98$ & $188 \pm 92$ & $198 \pm 103^{\star}$ & $<0.01,0.60^{a}$ & $\mathrm{NS}, 0.20^{b}$ & NS, $0.31^{c}$ \\
\hline & Peak leg force $(\mathrm{N})$ & $683 \pm 139$ & $742 \pm 99^{\star}$ & $791 \pm 139$ & $826 \pm 115^{\star}$ & $<0.001,0.82^{a}$ & $<0.05,0.42^{b}$ & $<0.05,0.42^{c}$ \\
\hline & Impulse of pole force $(\mathrm{N} \cdot \mathrm{s})$ & $110 \pm 51$ & $113 \pm 63$ & $95 \pm 40$ & $96 \pm 37$ & $<0.05,0.40^{a}$ & $\mathrm{NS}, 0.10^{b}$ & NS, $0.01^{c}$ \\
\hline & Impulse of leg force $(\mathrm{N} \cdot \mathrm{s})$ & $1080 \pm 300$ & $1160 \pm 250$ & $1020 \pm 270$ & $1090 \pm 220$ & $<0.001,0.76^{a}$ & $\mathrm{NS}, 0.24^{b}$ & NS, $0.30^{c}$ \\
\hline & Average cycle force $\left(\mathrm{N} \cdot \mathrm{S}^{-1}\right)$ & $601 \pm 148$ & $651 \pm 117^{\star}$ & $575 \pm 157$ & $655 \pm 106^{\star}$ & NS, $0.14^{a}$ & $<0.05,0.41^{b}$ & NS, $0.38^{c}$ \\
\hline & Impulse of forefoot force (N.S) & $698 \pm 217$ & $760 \pm 201^{*}$ & $696 \pm 241$ & $718 \pm 200$ & $<0.1,0.35^{a}$ & $\mathrm{NS}, 0.28^{b}$ & $<0.1,0.31^{c}$ \\
\hline & $\begin{array}{l}\text { Relative impulse of forefoot } \\
\text { force }(\%)\end{array}$ & $63 \pm 10$ & $64 \pm 13$ & $67 \pm 12$ & $67 \pm 12$ & $<0.01,0.54^{a}$ & NS, $0.08^{b}$ & $\mathrm{NS}, 0.02^{C}$ \\
\hline
\end{tabular}

${ }^{a}$ Main effect of speed.

${ }^{b}$ Main effect of carrying a rifle.

${ }^{c}$ Interaction effect, speed-rifle.

${ }^{\star} P<0.05$, in comparison with the corresponding value without a rifle.

NS, not statistically significant.

longer, 4.3 vs $3.9 \mathrm{~m}, P<0.05$ ), impulse of pole force (men, $50 \%$ more, 120 vs $80 \mathrm{~N} \cdot \mathrm{s}, P<0.01$ ), and peak pole force (men, 50\% larger, 187 vs $125 \mathrm{~N}, P<0.05$ ). No gender differences were observed with respect to gross efficiency and the metabolic cost of the task. While the absolute weight of the rifle was the same, there was a trend toward greater proportional rifle weight for the women $(P<0.1)$. An interaction effect between carrying a rifle and gender on $\dot{V}_{\mathrm{E}}$ was found $(P<0.05)$, with greater differences in women than those in men, while there was a trend toward a larger difference between $\mathrm{R}$ and NR with respect to BLa in our women biathletes $(P<0.1)$.

\section{DISCUSSION}

The major novel findings of the present investigation were as follows: 1) $\dot{\mathrm{VO}}_{2}, \dot{\mathrm{V}}_{\mathrm{E}}$, RER, HR, and BLa were higher $\left(\eta_{\mathrm{p}} \eta^{2}>0.72\right)$ when carrying a rifle than when not; 2$)$ cycle rate and leg forces were also higher when carrying a rifle $\left({ }_{\mathrm{p}} \eta^{2}>0.76\right)$, whereas pole force was only higher at racing speed and when using the V2 technique; 3) in disagreement with our hypothesis, no differences between the two skating techniques tested with respect to the influence of carrying a rifle were observed, even though V1 was performed at a greater incline $\left.\left(8 \mathrm{vs} 5^{\circ}\right) ; 4\right)$ except for greater $\dot{V}_{\mathrm{E}}$ in women, carrying a rifle exerts a similar effect on physiological and biomechanical parameters in women and men; 5) men demonstrated $25 \%-29 \%$ larger $\mathrm{V}_{2}$ and rates of metabolic and mechanical work, $11 \%$ longer cycle length, and $50 \%$ greater pole forces but the same gross efficiency and metabolic cost of the task as those of women; and, finally, 6) the rates of metabolic and mechanical work rate, gross efficiency, and metabolic cost of the task were higher with the V1 than those with the V2 technique.

TABLE 5. Kinematic and kinetic variables (mean \pm SD) while V1 skating at an absolute submaximal speed $\left(6 \mathrm{~km} \cdot \mathrm{h}^{-1}\right)$ or racing speed $\left(7.7 \mathrm{~km} \cdot \mathrm{h}^{-1}, 95 \% \mathrm{~V}_{2 \text { peak }}\right)$ and an incline of $8^{\circ}$ with or without a rifle $(n=10)$.

\begin{tabular}{|c|c|c|c|c|c|c|c|c|}
\hline \multirow[b]{3}{*}{ Cycle characteristics } & \multirow[b]{3}{*}{ Cycle time (s) } & \multicolumn{2}{|c|}{ Submaximal Speed } & \multicolumn{2}{|c|}{ Racing Speed } & & & \\
\hline & & \multirow{2}{*}{$\begin{array}{c}\text { NR } \\
1.52 \pm 0.14\end{array}$} & \multirow{2}{*}{$\frac{\mathbf{R}}{1.50 \pm 0.11}$} & \multirow{2}{*}{$\begin{array}{c}\text { NR } \\
1.36 \pm 0.13\end{array}$} & \multirow{2}{*}{$\frac{\mathbf{R}}{1.33 \pm 0.11^{*}}$} & \multicolumn{3}{|c|}{ ANOVA ( $P$ Value, $\left.p \eta^{2}\right)$} \\
\hline & & & & & & $<0.001,0.82^{a}$ & $<0.05,0.40^{b}$ & $\mathrm{NS}, 0.03^{c}$ \\
\hline & Cycle rate $(\mathrm{Hz})$ & $0.66 \pm 0.06$ & $0.67 \pm 0.05$ & $0.74 \pm 0.07$ & $0.76 \pm 0.06^{\star \star}$ & $<0.001,0.81^{a}$ & $<0.05,0.47^{b}$ & NS, $0.08^{c}$ \\
\hline & Cycle length (m) & $2.54 \pm 0.23$ & $2.50 \pm 0.19$ & $3.03 \pm 0.33$ & $2.96 \pm 0.33^{*}$ & $<0.001,0.84^{a}$ & $<0.05,0.44^{b}$ & NS, $0.08^{c}$ \\
\hline & Pole ground contact time (s) & $0.81 \pm 0.07$ & $0.80 \pm 0.08$ & $0.67 \pm 0.08$ & $0.66 \pm 0.07$ & $<0.001,0.83^{a}$ & $<0.1,0.35^{b}$ & $\mathrm{NS}, 0.02^{C}$ \\
\hline & Arm swing time (s) & $0.71 \pm 0.09$ & $0.71 \pm 0.09$ & $0.69 \pm 0.08$ & $0.67 \pm 0.06$ & $<0.05,0.38^{a}$ & NS, $0.17^{b}$ & $\mathrm{NS}, 0.09^{c}$ \\
\hline & Leg ground contact time (s) & $0.92 \pm 0.07$ & $0.92 \pm 0.07$ & $0.83 \pm 0.08$ & $0.81 \pm 0.07^{*}$ & $<0.001,0.87^{a}$ & $<0.05,0.47^{b}$ & NS, $0.19^{c}$ \\
\hline & Leg swing time (s) & $0.60 \pm 0.08$ & $0.59 \pm 0.06$ & $0.53 \pm 0.06$ & $0.53 \pm 0.05$ & $<0.001,0.77^{a}$ & $<0.1,0.28^{b}$ & $\mathrm{NS}, 0.02^{c}$ \\
\hline \multirow[t]{7}{*}{ Leg and arm kinetics } & Peak pole force (N) & $110 \pm 20$ & $108 \pm 17$ & $137 \pm 40$ & $137 \pm 24$ & $<0.001,0.72^{a}$ & NS, $0.01^{b}$ & NS, $0.03^{c}$ \\
\hline & Peak leg force (N) & $703 \pm 126$ & $737 \pm 132^{\star}$ & $754 \pm 134$ & $793 \pm 146^{\star *}$ & $<0.001,0.79^{a}$ & $<0.01,0.60^{b}$ & NS, $0.05^{c}$ \\
\hline & Impulse of pole force $(\mathrm{N} \cdot \mathrm{s})$ & $97 \pm 20$ & $92 \pm 15$ & $94 \pm 16$ & $96 \pm 18$ & NS, $0.00^{a}$ & NS, $0.03^{b}$ & $\mathrm{NS}, 0.22^{c}$ \\
\hline & Impulse of leg force $(\mathrm{N} \cdot \mathrm{s})$ & $800 \pm 235$ & $828 \pm 234$ & $726 \pm 209$ & $751 \pm 206$ & $<0.001,0.78^{a}$ & NS, $0.14^{b}$ & $\mathrm{NS}, 0.00^{c}$ \\
\hline & Average cycle force $\left(\mathrm{N} \cdot \mathrm{s}^{-1}\right)$ & $605 \pm 138$ & $629 \pm 147$ & $619 \pm 139$ & $652 \pm 144^{*}$ & $<0.1,0.35^{a}$ & $<0.1,0.36^{b}$ & NS, $0.07^{c}$ \\
\hline & Impulse forefoot force $(\mathrm{N} \cdot \mathrm{s})$ & $545 \pm 153$ & $548 \pm 154$ & $525 \pm 148$ & $527 \pm 153$ & $<0.5,0.44^{a}$ & NS, $0.01^{b}$ & $\mathrm{NS}, 0.00^{c}$ \\
\hline & Relative impulse forefoot force (\%) & $69 \pm 10$ & $67 \pm 9$ & $73 \pm 9$ & $71 \pm 9$ & $<0.01,0.57^{a}$ & $<0.05,0.37^{b}$ & NS, $0.00^{c}$ \\
\hline
\end{tabular}

Main effect of speed.

${ }^{b}$ Main effect of carrying a rifle.

Interaction effect, speed-rifle.

${ }^{\star} P<0.05$ in comparison with the corresponding value without a rifle.

${ }^{\star \star} P<0.01$, in comparison with the corresponding value without a rifle.

NS, not statistically significant. 
Our biathletes exhibited greater cardiopulmonary response, higher RER, more pronounced increase in BLa, and higher rate of metabolic work when skiing with a rifle than without. However, the higher oxygen cost observed here was only about half of that reported by Rundell and Szmedra (20), a difference that might be explained by differences in the performance level of the subjects (our senior vs their junior skiers), developments in skiing equipment (roller skis and poles) and improvements in the geometry of and strap system for mounting the rifle and in training status (i.e., more specific training, increased proportion of roller ski training, altered regimens for training strength, etc.) that have occurred in the 15 years since their report. It is important to note that our subjects were all current or former members of the Swedish Senior National Team. Furthermore, the smaller differences found in the current study might reflect the different skiing techniques used (V2 alternate earlier vs V1 and V2 here), although future research should address this possibility.

The mean rifle weight was $4.0 \pm 0.2 \mathrm{~kg}$ (in comparison with the minimum weight of $3.5 \mathrm{~kg}$ allowed in biathlon). Previous characterizations of load carrying have generally involved walking rather than skiing and typically much heavier loads $(7,15,18)$. The equation proposed by Pandolf et al. (18) to estimate the energy expenditure of carrying a load as a function of the walking speed and the road incline predicts that, for a $4-\mathrm{kg}$ load at $8 \mathrm{~km} \cdot \mathrm{h}^{-1}$ on an asphalt road with an incline of $5^{\circ}$, the metabolic power requirement is $931 \mathrm{~W}$, which is equivalent to a $\mathrm{VO}_{2}$ of $3.33 \mathrm{~L} \cdot \mathrm{min}^{-1}$ at an RER of 0.9 . This is only slightly higher than the observed $\dot{\mathrm{V}} \mathrm{O}_{2}$ of $3.18 \pm 0.38 \mathrm{~L} \cdot \mathrm{min}^{-1}$ while skiing with $\mathrm{R}$ using the $\mathrm{V} 2$ technique on the same incline and at the same speed, a difference of $-5 \%$ that is surprisingly small in light of the differences between walking and skiing, especially at the high skiing speed tested. For skiing at $6 \mathrm{~km} \cdot \mathrm{h}^{-1}$ on an incline of $8^{\circ}(14.1 \%)$, the values provided by this equation differed a bit more, predicting a $\dot{\mathrm{VO}}_{2}$ of $2.93 \mathrm{~L} \cdot \mathrm{min}^{-1}$ at an RER of 0.92 , compared with our observed $3.30 \mathrm{~L} \cdot \mathrm{min}^{-1}$, i.e., $11 \%$ higher for skiing. It seems, therefore, that in cross-country skiing, slope has a more pronounced effect on metabolic cost than in walking (with an added mass) at the same speed. Finally, the increase in energy cost of rifle carriage was not directly related (ratio, 1.0 ) to the mass of the supported load (as indicated by Taylor et al. (29) in small and large animals) but revealed a slightly lower increase in $\mathrm{VO}_{2}$ compared with the increase in extra load (ratio, 0.97).

The additional weight of the rifle led to an increase in the power output against gravity and friction of approximately $11 \mathrm{~W}(212 \mathrm{vs} 222 \mathrm{~W})$. The skiers were forced to adapt to the enhanced system mass and consequent requirement for elevated power output by accelerating the cycle rate and producing larger peak leg and average cycle forces. Only when skiing with the V2 technique at racing speed was carrying a rifle associated with an enhanced contribution of pole forces. This observation might reflect the more extensive contribution of pole forces to propulsion during V2 than V1 skating (25) but could also be due to differences between these techniques with respect to trunk motion. To be noted here, only the minimum external work as work against gravity and friction was calculated. Therefore, the potential effects of carrying a rifle on whole body motion and their consequences for internal work (of body segments with respect to the center of mass) and external work (motion of the center of mass with respect to the surroundings) need to be analyzed more fully using three-dimensional kinematics.

Accordingly, the greater metabolic and cardiorespiratory responses when carrying a rifle might be attributed to the larger power output required and achieved mainly by increasing leg work and cycle rate (which is a less economic situation associated with lower peak performance, as shown previously $(26,28))$. Perhaps, not only the additional weight but also carrying the rifle and wearing its harness might contribute to these alterations in skiing technique and physiological responses. These findings highlight that skiing with a rifle with either skating technique places special demands on the lower body and, during V2, on the upper-body as well, factors that should be considered when designing training regimens for biathletes.

Even though carrying a rifle enhanced the rates of mechanical and metabolic work, gross efficiency remained unaltered at approximately $16 \%$. Under all conditions, this gross efficiency was greater with the $\mathrm{V} 1\left(8^{\circ}\right)$ than that with the V2 $\left(5^{\circ}\right)$ skating technique, in line with a recent report by Sandbakk et al. $(23,24)$ on cross-country skiers. Furthermore, it was assumed that the differences in skiing techniques between V1 and V2 might have affected the physiological and biomechanical response because of the asymmetric characteristics with slight rotational components in the trunk motion in V1 (27) when compared with those in V2. However, in contrast to what we expected, there were no differences between the two skating techniques with respect to the effect of carrying a rifle on physiological and biomechanical variables, even though V1 was performed on a steeper incline $\left(8^{\circ}\right.$ vs $\left.5^{\circ}\right)$ that required greater vertical work, and the rates of mechanical work and metabolic work were more pronounced $(+11 \%)$ with the rifle. Thus, the influence of carrying a rifle seemed to be independent of technique and grade in the present study.

Our male biathletes skied with $11 \%$ longer cycles than the women, with no difference in cycle rate, partly agreeing with the findings of Sandbakk et al. (22) in cross-country skiing. These investigators demonstrated that when V2 skating at the same absolute speed, men used $11 \%$ longer cycles at lower rates and $21 \%$ longer cycle lengths at peak speed when using V2. Although there were no differences in leg or average cycle forces in our current trials, the men applied $50 \%$ greater peak pole forces along with $50 \%$ higher impulse of pole force, with no interaction between techniques. Sandbakk et al. (21) found more pronounced gender differences in association with modes of exercise in which the upper body is more involved. This reveals considerable 
potential for development of upper body performance of women that should be taken into special consideration when designing training regimens for all cross-country skiing disciplines, including the biathlon. With respect to the gross efficiency and metabolic cost of the task (which reflect the energy cost per kilogram per meter), no gender differences were observed, confirming the findings of Sandbakk et al. (23).

Moreover, we also observed no difference between men and women with respect to the influence of carrying a rifle on biomechanical variables. This is somewhat in contrast to the report by Rundell and Szemdra (20) that when skiing at a speed of $2.91 \mathrm{~m} \cdot \mathrm{s}^{-1}$ using the V2 alternate technique at an incline of $4.6^{\circ}(8 \%)$, carrying a rifle reduced the cycle length used by men but not that used by women. However, this difference might also have been related to the fact that their female biathletes were members of the Women's Senior National Team whereas the men belonged to the Junior National Team.

The absence of any gender differences in the effects of carrying a rifle observed here might reflect the different racing speeds of the men and women as well as differences in body weight and the greater rifle mass relative to body mass in women. However, even when the rate of metabolic work was expressed relative to body mass and skiing velocity (metabolic cost of the task), no interaction between gender and carrying a rifle was found.

\section{REFERENCES}

1. Andersson E, Supej M, Sandbakk O, Sperlich B, Stöggl T, Holmberg HC. Analysis of sprint cross-country skiing using a differential global navigation satellite system. Eur J Appl Physiol. 2010;110(3):585-95.

2. Baca A, Kornfeind P. Stability analysis of motion patterns in biathlon shooting. Hum Mov Sci. 2012;31(2):295-302.

3. Bassett DR Jr, Howley ET. Limiting factors for maximum oxygen uptake and determinants of endurance performance. Med Sci Sports Exerc. 2000;32(1):70-84.

4. Coote JH. Recovery of heart rate following intense dynamic exercise. Exp Physiol. 2010;95(3):431-40.

5. di Prampero PE, Ferretti G. The energetics of anaerobic muscle metabolism: a reappraisal of older and recent concepts. Respir Physiol. 1999;118(2-3):103-15.

6. Fredrick EC. Estimates of the energy cost of rifle carriage in biathlon ski skating. Int J Sports Biomech. 1987;3(4):392-403.

7. Grabowski A, Farley CT, Kram R. Independent metabolic costs of supporting body weight and accelerating body mass during walking. J Appl Physiol (1985). 2005;98(2):579-83.

8. Grebot C, Groslambert A, Pernin JN, Burtheret A, Rouillon JD. Effects of exercise on perceptual estimation and short-term recall of shooting performance in a biathlon. Percept Mot Skills. 2003; 97(3 Pt 2):1107-14.

9. Groslambert A, Candau R, Grappe F, Dugue B, Rouillon JD. Effects of autogenic and imagery training on the shooting performance in biathlon. Res Q Exerc Sport. 2003;74(3):337-41.

10. Groslambert A, Candau R, Hoffman MD, Bardy B, Rouillon JD. Validation of simple tests of biathlon shooting ability. Int J Sports Med. 1999;20(3):179-82.

\section{CONCLUSIONS}

These findings indicate that from a physiological and biomechanical perspective, training with a rifle is more demanding. Comparison with earlier studies suggests that more and more effective training (involving more specific biathlon training), developments in skiing equipment, and improvements in rifle construction can reduce the extra energy costs of carrying a rifle, emphasizing the need to devote more training time to skiing with a rifle. The greater load on the lower body when carrying a rifle and the considerable potential for development of upper body performance of female biathletes should be given special consideration when designing training regimens. In conclusion, our current findings reveal that carrying a rifle enhances physiological and biomechanical demands, requiring significantly more leg work and an increase of cycle rate. These effects were not dependent on skiing technique and were dependent on gender only to a minor extent.

The authors thank the athletes involved in this study for their participation, enthusiasm, and cooperation.

This investigation was supported financially by the Swedish National Centre for Research in Sports (CIF).

None of the authors had any personal or financial conflicts of interest.

The reporting of these findings does not constitute endorsement by the American College of Sports Medicine.

11. Groslambert A, Grappe F, Rouillon JD. Réponses cardioventilatoires au tir debout en biathlon [Ventilatory adaptations during biathlon shooting]. Sci Sport. 1998;13(3):135-7.

12. Heglund NC, Willems PA, Penta M, Cavagna GA. Energy-saving gait mechanics with head-supported loads. Nature. 1995;375(6526): $52-4$.

13. Hoffman MD, Street GM. Characterization of the heart rate response during biathlon. Int J Sports Med. 1992;13(5):390-4.

14. Holmberg HC, Lindinger S, Stöggl T, Eitzlmair E, Müller E. Biomechanical analysis of double poling in elite cross-country skiers. Med Sci Sports Exerc. 2005;37(5):807-18.

15. Knapik J, Harman E, Reynolds K. Load carriage using packs: a review of physiological, biomechanical and medical aspects. Appl Ergon. 1996;27(3):207-16.

16. Laaksonen MS, Ainegren M, Lisspers J. Evidence of improved shooting precision in biathlon after 10 weeks of combined relaxation and specific shooting training. Cogn Behav Ther. 2011;40(4): 237-50.

17. Lakie M. The influence of muscle tremor on shooting performance. Exp Physiol. 2010;95(3):441-50.

18. Pandolf KB, Givoni B, Goldman RF. Predicting energy expenditure with loads while standing or walking very slowly. $J$ Appl Physiol Respir Environ Exerc Physiol. 1977;43(4):577-81.

19. Peronnet F, Massicotte D. Table of nonprotein respiratory quotient: an update. Can J Sport Sci. 1991;16(1):23-9.

20. Rundell KW, Szmedra L. Energy cost of rifle carriage in biathlon skiing. Med Sci Sports Exerc. 1998;30(4):570-6.

21. Sandbakk O, Ettema G, Holmberg HC. Gender differences in endurance performance by elite cross-country skiers are influenced 
by the contribution from poling. Scand J Med Sci Sports. 2014; 24(1):28-33.

22. Sandbakk O, Ettema G, Leirdal S, Holmberg HC. Gender differences in the physiological responses and kinematic behaviour of elite sprint cross-country skiers. Eur J Appl Physiol. 2012;112(3):1087-94.

23. Sandbakk O, Hegge AM, Ettema G. The role of incline, performance level, and gender on the gross mechanical efficiency of roller ski skating. Front Physiol. 2013;4:293.

24. Sandbakk O, Holmberg HC, Leirdal S, Ettema G. Metabolic rate and gross efficiency at high work rates in world class and national level sprint skiers. Eur J Appl Physiol. 2010;109(3):473-81.

25. Smith GA, Kvamme B, Jakobsen V. Effectiveness of ski and pole forces in ski skating. In: Müller E, Lindinger S, Stöggl T, editors. Science and Skiing $I V$. Maidenhead (United Kingdom): Meyer \& Meyer Sport, 2009. pp. 647-56.
26. Stöggl T, Björklund G, Holmberg HC. Biomechanical determinants of oxygen extraction during cross-country skiing. Scand $J$ Med Sci Sports. 2013;23(1):e9-20.

27. Stöggl T, Hébert-Losier K, Holmberg HC. Do anthropometrics, biomechanics, and laterality explain V1 side preference in skiers? Med Sci Sports Exerc. 2013;45(8):1569-76.

28. Stöggl T, Müller E, Ainegren M, Holmberg HC. General strength and kinetics: fundamental to sprinting faster in cross country skiing? Scand J Med Sci Sports. 2011;21(6):791-803.

29. Taylor CR, Heglund NC, Mcmahon TA, Looney TR. Energetic cost of generating muscular force during running - a comparison of large and small animals. J Exp Biol. 1980;86:9-18.

30. Vickers JN, Williams AM. Performing under pressure: the effects of physiological arousal, cognitive anxiety, and gaze control in biathlon. J Mot Behav. 2007;39(5):381-94. 